\title{
Chapter 22 \\ Walking Together: Ways of Collaboration in Western-Indigenous Research on Footprints
}

\author{
Hannah Zwischenberger
}

\begin{abstract}
A combination of western analytical methods with experience-based indigenous methods of tracking can be a chance to get closer to individuals of past times. In such collaborative research projects, different western and indigenous knowledge systems meet. These are characterized in more detail below. This chapter examines the question of how respectful and mutually beneficial cooperation is possible against the background of different epistemologies. Recommendations for practical action in collaborative projects are summarized in an ethics guide and an interview guide, and alternative forms of writing and publication are proposed.
\end{abstract}

Keywords Interpreting footprints $\cdot$ Knowledge systems $\cdot$ Indigenous epistemology $\cdot$ Research framework $\cdot$ Research partnership $\cdot$ Holistic paradigm . Ethic guideline $\cdot$ Interview guideline $\cdot$ Narrative approaches $\cdot$ Subjective knowledge Community report $\cdot$ Personal journal $\cdot$ Alternative publication

\section{Introduction}

Since the beginning of human history, people have left their mark all over the world, as can be seen from the large number of archaeological finds (e.g. Cherin et al. Chap. 8; Ashton Chap. 9; Kyparissi-Apostolika and Manolis Chap. 10) and articles on them (e.g. Kim 2008; Lockley et al. 2008). The interpretation of archaeological footprints opens up the possibility of getting closer to individuals of past times in a particularly direct way. A person's footprint is as individual as a fingerprint (Lowe 2002: 68) and can refer to specific identity characteristics such as gait speed, age and gender, as well as to action scenarios reflected in traces.

\footnotetext{
H. Zwischenberger $(\square)$

University of Cologne, Cologne, Germany

e-mail: hannah.zwischenberger@posteo.de
} 
As the history and diverse results of the conference show, footprints are an object of investigation that is relevant both for western researchers of different disciplines and for indigenous communities. The parameters studied are partly similar, while the contexts and methods of interpretation differ. Bennett and Morse (2014) and Liebenberg (1990) give an overview of western morphometrical and indigenous experience-based methods of trace interpretation.

Interpretation methods are embedded in larger knowledge systems. Epistemological questions on the emergence, transmission, validation and possession of knowledge are crucial not only for the method itself but also for the entire research process. The focus of this article is therefore on the traces that the researchers themselves leave behind in the field of collaborative projects:

Leaving a trace means "an action that depends on knowing how to live and leave information for others to follow" (Legat 2008: 37). Umbagai's statement "As a tracker you end up being a person that is being tracked" (pers. comm. Umbagai 2017) can also be understood in this sense.

People move in networks of knowledge and relationships and are always tracker and trackmaker at the same time. What does this mean for the cooperation of western and indigenous trace experts with their different epistemological backgrounds?

Essential characteristics of western and indigenous knowledge systems will be discussed in more detail below. Subsequently, both systems, often perceived as contrary, are related to each other. The image of the networked space forms the basis for practical and ethical considerations on cooperation. What a dialogue based on partnership can actually look like and which aspects are important in this context is made clear in a guideline developed for trace projects. This is followed by a section that examines communicative aspects of the interpretation and validation of the traces investigated. Interpretative conversations at the site are regarded as an interview in the broad sense, and concrete suggestions are summarized in a guideline.

At the end of the research process stands the communication of the results. How the hypothesis developed on the basis of the track read and also how the research itself is communicated is therefore the final topic. In addition to specialist publications and lectures, many other forms between written and oral narratives are possible. Some of them will be presented here, also from the point of view of subjectivity and reciprocity.

Examples of western-indigenous research projects exist from archaeological excavations (Colwell-Chanthaphonh and Ferguson 2008), cultural heritage management (Hollowell and Nicolas 2009), cave art (Rouzaud and Jamet 1993) and material culture/museum (Reyels et al. 2018). Many such projects are based on the community-based participatory research (CBPR) approach, which is characterized by partnership at all stages of the research process (Atalay 2012: 51). In particular, aspects of civil society cooperation and fair benefits are also emphasized by Michael Robinson, who draws a parallel between One World Economy and One World Science with his participatory action research (Robinson 1996). Is fair trade in knowledge the key to a mutually beneficial research partnership? Knowledge as an asset to be acquired and as personal property: This representation reflects an individualistic concept typical of western knowledge systems. 


\section{Western and Indigenous Knowledge Systems}

Western knowledge systems are hierarchically structured and often associated with the concept of distance (Studley 1998: 9; Smith 1999). The researcher is the expert who needs the distance to the research object to be able to see it up close. Distance, which is seen as a more or less measurable value, implies a neutrality and objectivity of the researcher. It is often assumed that there is only in sciences one reality that can be expressed in laws. An essential feature of western knowledge is therefore that it is based on the hypothesis of a basic mathematical structure of nature (Hountondji 2002: 27; Porr and Matthew 2016: 246). The relationship between man and nature and related concepts influences epistemological questions in many ways. The separation of culture and nature is part of the great dichotomies that have been reinforced since the era of Enlightenment and are reflected in positivist paradigms. The Age of Reason as a response to church dogmas led to classification and representation systems:

which lend themselves easily to binary oppositions, dualisms, and hierarchical ordering of the world. (Smith 1999: 55)

Such oppositions are deeply rooted in western epistemologies, even though since the Enlightenment, many turns and shifts have led to new directions of thought and today holistic paradigms are more likely to be sought (Studley 1998: 6). Aspects of these holistic paradigms are interdisciplinary and intercultural cooperation and the integration of indigenous knowledge into the academy. This can be both a chance and a challenge:

The big dilemma and struggle is doing that in a western-indigenous research context, trying to grow something Indigenous there. Out of a box, you're morphing a circle and there is something kind of wacky about that, but there is something kind of challenging about that, too [laughter]. (Absolon in Kovach 2009: 153)

Western and indigenous knowledge systems are summarized here in their basic forms: The box can be seen as a collection of data as result orientation and also contains research conventions, guidelines, time and financial framework conditions. The circle, on the other hand, emphasizes relational and communicative aspects of research and process orientation. In order to bring the two together, it is necessary to be aware of the differences and similarities between western and indigenous knowledge systems.

\section{Differences and Similarities}

There is a broad consensus that indigenous knowledge is location- and culturebound and dynamic and that it has a contrary relationship to western academic knowledge (Studley 1998: 4-6). Arun Agrawal is particularly critical of the latter point. He considers the dichotomy of "western versus indigenous knowledge" to be 
problematic in principle, since it illustrates western traditions of binary thinking rather than actual knowledge characteristics, and there are also great similarities between the two categories as well as differences within one category (Agrawal 1995: 421).

It is often suggested that indigenous knowledge is primarily concerned with activities related to the immediate world (or even mere survival), as opposed to general analytical abstract models, ideas and philosophies typical of the western world. The point of local knowledge may apply to highly specific environmental knowledge. However, indigenous knowledge goes far beyond this and vice versa; western science also often refers to everyday problem-solving strategies (Agrawal 1995: 423). The distinction local/universal is therefore insufficient to define both forms of knowledge. Knowledge is never universal, neither western nor indigenous. Both forms are locally produced ethno-knowledges (Kincheloe and Steinberg 2006: 150). This insight facilitates an equal and open exchange in joint projects.

Methodological differences between the two knowledge systems that are important for practical cooperation can be found in the epistemological orientation and the different relationship between implicit and explicit knowledge. In indigenous systems, subjectivity is assumed and recognized as a natural source of knowledge (Kovach 2009: 11) but has little place in institutionalized western systems, where it is often regarded as the enemy of objectivity. This conflict can also be seen in joint projects when it comes to the verifiability of experience-based methods or guidelines for scientific writing. It is anchored in epistemologies that initially seem contradictory. In contrast to western epistemologies, in which knowledge is classified in hierarchical systems and predominantly handed down in writing, the focus of indigenous epistemologies is different:

If indigenous ways of knowing have to be narrowed through one particular lens (which it certainly does not), then surely that lens would be relationality. (Wilson 2008: 58)

\section{Relationality and Validity}

Relationality is a fundamental element of indigenous knowledge systems that permeates all aspects of knowledge. It refers not only to interpersonal relations but also to those with the cosmos and the environment. In such an interwoven, non-linear understanding of knowledge, theories and ideas are not guard rails on a straight road of knowledge, but:

only knots in the strands of relationality that are not physically visible but are nonetheless real. (Wilson 2008: 87)

The environment is not a passive object of knowledge; it is also knowledge itself. The close connection between people and the country as a teacher is also of great importance in reading traces, as Leah Umbagai (Dambimangari Aboriginal Corporation, Australia) makes clear at the conference on prehistoric human footprints in Cologne (Fig. 22.1): 
Fig. 22.1 Leah Umbagai (Australia) surrounded by other international tracking experts during the Prehistoric Human Tracks conference in Cologne/ Mettmann 2017; from left to right: Tsamgao Ciqae (Namibia), Leah Umbagai, /Ui Kxunta (Namibia), George Aklah (Canada) and Thui Thao (Namibia). (Photo H. Specht/J. Becker)

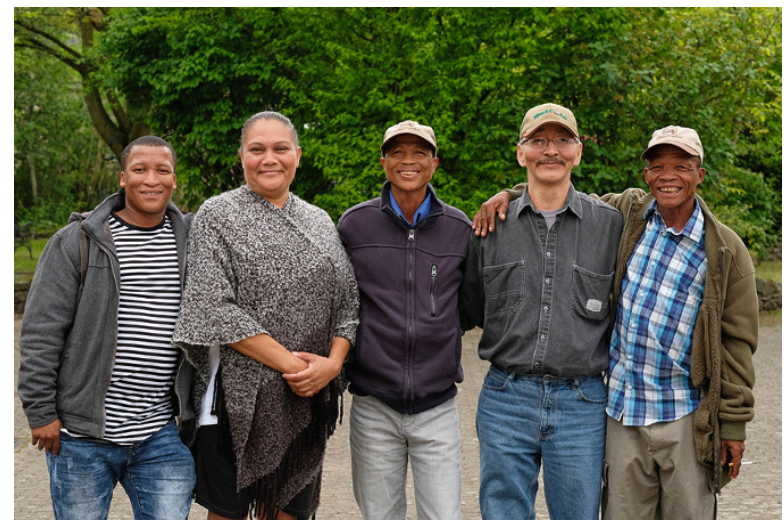

When you're trying to understand tracking, it's also understanding the character of people, how they walk, understanding the animals, where they come from (...). So, the country, it teaches you the tracking. (...) Everything is there, it's a matter of really taking note, and watching, listening. (Umbagai 2017)

Access to knowledge is created through the awareness of being part of a larger interdependent network of relationships and through precise observation and sensory perceptions.

The question which realities and forms of knowledge are culturally accepted is related to the question of how knowledge is validated. In indigenous knowledge systems, validity is not an abstract measurable value, but, like the other aspects of knowledge, is integrated into relational dynamics. Validation of knowledge is oriented towards cultural rules of knowledge production and representation and is "based on time-honoured and proven principles" (Bishop 1999: 4).

Instead of a measurable validity, the concept of relational accountability (Wilson 2008) or "social accountability" (Studley 1998: 11) can also be used. Reliability in such an understanding does not refer exclusively to knowledge and research data, but is associated with the reliability of social relationships (Wilson 2008: 77). Relationships live through communication. Communicative validation of knowledge through interpretative discourse and consensus building within a group is a particularly relevant validation option for joint projects in trace research.

Following on from the point of relationality, the question now arises as to how western and indigenous knowledge can be related to one another in joint projects. The question of from which direction do we begin research can be extended to the question how can we come together and find a common direction. We do not start at one end, but in the middle. From there we take a look at our field of action, our environment and the ground that supports us and plan our route. 


\section{The Networked Space}

In order to build the research framework on a sustainable basis and to plan joint steps, it is important to not only take differences into account but also to look the similarities of knowledge systems. In the academy, some holistic approaches similar to indigenous epistemologies can be found. For example, Tim Ingold's concept of meshwork can be compared with indigenous horizontal educational concepts.

\section{Horizontal Structures of Living and Learning}

The environment, the space in which people move, is characterized as a relational network. According to Ingold, this meshwork is not a complex of interconnected points, but a network of interwoven life paths and traces of movement. The connecting points are not to be seen as static units that can be analysed mathematically, but as points of concentration of knowledge and experience that have grown out of the intersection of life paths and are constantly being formed anew. Knowledge as an open and flowing process is integrated:

along paths of movement, and people grow into it by following trails through a meshwork.

(Ingold 2011: 143)

This moving learning and knowledge in motion is described by the term wayfaring. All participating researchers are involved in interpretative processes as wayfaring knowledge-seekers. Research and learning are processes of "reweaving rather than receiving" (Smith 1999: 532).

\section{Horizontal Structures of Power}

Horizontal power structures and ethical aspects of cooperation are also associated with such a horizontal understanding of education. Furthermore, they are also important from a postcolonial point of view, because ethics is "emerging from historic relationships with research" (Kovach 2006: 69). In colonial times, research on indigenous peoples served western interests. The production mode of the colonial pact with its continuous exploitation of resources and flooding with products to stabilize power applies equally to material production goods and knowledge production (Hountondji 2002). The processes of marginalization rooted in this period and the ideology of the oppositions

- Western - indigenous

- Centre - periphery

- Systematic - unsystematic

- Rational - empirical 
have an effect in many ways even to this day (Smith 1999; Jones and Jenkins 2008). The western tradition of binary thought also raises questions in partnership: Does indigenous knowledge not have to be validated with western analytical methods in order to be perceived as scientifically correct? Or should western knowledge be validated by indigenous knowledge? Both approaches would assume that there is already a favoured truth that is subsequently subjected to control by the other knowledge system. However, a collaborative project aims at the participation of indigenous experts in all stages of the research process. The joint interpretation of the traces and communicative validation are in the foreground. Narrative approaches can contribute to a good basis for joint projects. In the 1970s, the "narrative turn" marked the beginning of a development in academia in which narration was increasingly recognized as a mode of knowledge. It was no longer exclusively an object of research, but became itself a lamp through which other aspects of life and research could be made visible (Kreiswirth 1994: 62). Accordingly, each researcher has his own headlamp (narration/knowledge) in joint projects of trace interpretation, which helps to illuminate the path to the true core of a hypothesis.

Walking and working together in this sense is only possible if a communicative space or middle ground characterized by trust and respect has been created in advance of the interpretation of the traces. A "communicative space/middle ground" provides an opportunity for an open exchange. It:

can be considered both metaphorical and literal, as defined and operationalized by the group in question. (Lyons 2011: 86)

Fundamentally important aspects of this space are being present, communicating, listening, respect and understanding (Tondu et al. 2014). Especially from a postcolonial and critical point of view, indigenous knowledge and ethical aspects are to be considered not only as part of the research framework but as the heart of the research. They are, in the truest sense of the word, fundamental to all steps in the research process.

Indigenous epistemology can act as a reference point for ethical research. Kovach gives an example of this by comparing the knowledge of the Plains Cree of North America associated with buffalo hunting with research processes. Hunting requires thorough preparation, protocol, method, respect and sharing of prey. Similarly, research includes the preparation of the researcher and the research, the recognition of cultural and ethical protocols, respect and knowledge sharing (Kovach 2009: 65). Self-reflexivity and belonging and openness and care in research as the basis of method choice help to track prey/knowledge. The successful outcome of hunt/ research depends on a respectful attitude, the application of cultural and ethical protocols and good communication and cooperation between hunters and / (analog to the previous comparison "hunter/researcher", "prey/knowledge", means rather the cooperation within a hunting or research group) researchers. 


\section{Implementing Ethics in Research}

The process of tracking is an "ongoing process of problem-solving" (Liebenberg 1990: 89), and the same applies to the research process: clear agreements on various topics and decisions are necessary. In order to ensure that this dialogue takes place at eye level, in recent years and decades, many indigenous communities have drafted their own ethical guidelines or participated in the creation of such guidelines. These differ in the scope and specification of individual topics, but largely coincide in the main topics addressed. In the following, five ethics guidelines will be compared as examples and summarized in Table 22.1, in order to then concretize relevant points in an ethics guideline that can be used for trace projects.

\section{Indigenous Guidelines}

The aim of the Royal Commission on Aboriginal People (RCAP) is to provide a new basis to relations between western and indigenous people and political representatives that are described as being based on false premises (Summary final report). The report, published in 1996, focuses on political, social and cultural issues. Researchers from all over Canada submitted proposals on ethics. The resulting guideline is applicable to work with both individuals and indigenous groups in different contexts.

The Dene Cultural Institute (DCI) in Canada describes in a detailed guideline a participatory approach especially for research concerning traditional ecological knowledge. Some aspects of the guide are very local- or topic-specific, while others are transferable to other research contexts. The Inuit Research Guideline of the Inuit organization Inuit Tapiriit Kanatami also originates from Canada. It includes 12 points on consent, communication and access to research data (Grenier 1998: 87-88). The Guidelines for Ethical Research in Australian Aboriginal Studies were published in 2012 by the Australian Institute of Aboriginal and Torres Islander Studies (AIATSIS) and comprise 14 research principles with associated practical recommendations. A current guideline from South Africa is the San Code of Research Ethics of the South African San Institute (SASI). This guideline, published in 2017, is divided into five main topics: respect, honesty, justice and fairness, care and process. These generic terms are also reflected in other, common core points of the ethics guidelines presented. All these guidelines deal with consent, the type of participation, the handling of data and reciprocity.

Important points concerning content and objectives of research, type of participation, funding, etc. should be written down and signed. This step should be seen as a joint design process, during which, in exchange with indigenous communities and organizations, the project plan is discussed and research ideas are jointly developed (SASI 2017). The term cooperative agreement (DCI 1991) instead of informed consent makes this communicative aspect particularly clear. 
Table 22.1 Different guidelines for ethical research with indigenous peoples

\begin{tabular}{|c|c|c|c|c|}
\hline guideline & Consent & Participation & Data & Reciprocity \\
\hline $\begin{array}{l}\text { RCAP } \\
\text { (1996) }\end{array}$ & $\begin{array}{l}\text { Informed consent } \\
\text { signed by individ- } \\
\text { uals, groups or } \\
\text { representatives } \\
\text { Objectives and } \\
\text { aims of research, } \\
\text { benefits and risks }\end{array}$ & $\begin{array}{l}\text { Participation in } \\
\text { planning, imple- } \\
\text { mentation and } \\
\text { evaluation } \\
\text { Revision of } \\
\text { research results } \\
\text { before publication }\end{array}$ & $\begin{array}{l}\text { Final reports: } \\
\text { Open public access } \\
\text { Distribution in } \\
\text { local communities, } \\
\text { using the indige- } \\
\text { nous language }\end{array}$ & $\begin{array}{l}\text { Community bene- } \\
\text { fits } \\
\text { Influence of the } \\
\text { research at local, } \\
\text { regional or } \\
\text { national level } \\
\text { Supporting indig- } \\
\text { enous research }\end{array}$ \\
\hline $\begin{array}{l}\text { DCI } \\
(1991)\end{array}$ & $\begin{array}{l}\text { Joint/cooperative } \\
\text { agreement } \\
\text { Several meetings } \\
\text { with local commu- } \\
\text { nity } \\
\text { Objectives of } \\
\text { research, method- } \\
\text { ology, commit- } \\
\text { ments and benefits } \\
\text { Signed by commu- } \\
\text { nity } \\
\text { representatives }\end{array}$ & $\begin{array}{l}\text { Community } \\
\text { administrative } \\
\text { committee } \\
\text { Indigenous and } \\
\text { western represen- } \\
\text { tatives } \\
\text { Elders Council } \\
\text { Assistance in } \\
\text { interpretation, rec- } \\
\text { ommendation for } \\
\text { the selection of } \\
\text { community } \\
\text { researchers } \\
\text { Training } \\
\text { programme cross- } \\
\text { cultural, interdis- } \\
\text { ciplinary approach }\end{array}$ & $\begin{array}{l}\text { Release form at the } \\
\text { beginning of an } \\
\text { interview } \\
\text { concerning the } \\
\text { type of access to } \\
\text { information (who, } \\
\text { when) } \\
\text { Progress reports } \\
\text { and a summary of } \\
\text { the final report in } \\
\text { the indigenous lan- } \\
\text { guage } \\
\text { Community news- } \\
\text { letter, video of the } \\
\text { work, etc. }\end{array}$ & $\begin{array}{l}\text { Remuneration of } \\
\text { the community } \\
\text { researchers } \\
\text { according to effort } \\
\text { and working } \\
\text { hours } \\
\text { Decision of the } \\
\text { community } \\
\text { administrative } \\
\text { committee }\end{array}$ \\
\hline ITC & $\begin{array}{l}\text { Informed consent } \\
\text { Purpose of } \\
\text { research, sponsors, } \\
\text { involved persons } \\
\text { and institutions, } \\
\text { methodology, type } \\
\text { of cooperation }\end{array}$ & $\begin{array}{l}\text { Ongoing commu- } \\
\text { nication on objec- } \\
\text { tives, methods, } \\
\text { interpretation, } \\
\text { results } \\
\text { Integration of } \\
\text { indigenous knowl- } \\
\text { edge in all stages } \\
\text { of the research } \\
\text { process }\end{array}$ & $\begin{array}{l}\text { Access to raw data, } \\
\text { not just summaries } \\
\text { should be part of } \\
\text { the consent form }\end{array}$ & $\begin{array}{l}\text { Training of indig- } \\
\text { enous researchers } \\
\text { Sharing informa- } \\
\text { tion and research } \\
\text { results in the } \\
\text { appropriate lan- } \\
\text { guage(s) }\end{array}$ \\
\hline $\begin{array}{l}\text { SASI } \\
\text { (2017) }\end{array}$ & $\begin{array}{l}\text { Prior informed } \\
\text { consent based on } \\
\text { honesty in the } \\
\text { communications } \\
\text { Research idea that } \\
\text { is collectively } \\
\text { designed }\end{array}$ & $\begin{array}{l}\text { Open and continu- } \\
\text { ous mode of com- } \\
\text { munication, clear } \\
\text { not academic lan- } \\
\text { guage, absolute } \\
\text { transparency, open } \\
\text { exchange }\end{array}$ & $\begin{array}{l}\text { Contribution to } \\
\text { research is } \\
\text { acknowledged at } \\
\text { all times } \\
\text { Subsequent } \\
\text { publications }\end{array}$ & $\begin{array}{l}\text { Co-research } \\
\text { opportunities, } \\
\text { sharing of skills } \\
\text { and research } \\
\text { capacity, roles for } \\
\text { translators and } \\
\text { research assistants }\end{array}$ \\
\hline $\begin{array}{l}\text { AIATSIS } \\
(2012)\end{array}$ & $\begin{array}{l}\text { Full prior informed } \\
\text { consent: Objec- } \\
\text { tives of research, } \\
\text { aims, all partici- } \\
\text { pants and involved } \\
\text { institutions, } \\
\text { funding sources, }\end{array}$ & $\begin{array}{l}\text { Define project } \\
\text { phases and regu- } \\
\text { larly reflect on } \\
\text { methods, results } \\
\text { and research pro- } \\
\text { cess } \\
\text { Participation in }\end{array}$ & $\begin{array}{l}\text { Written agree- } \\
\text { ments on presenta- } \\
\text { tion, access and } \\
\text { ownership of data, } \\
\text { rights of use (insti- } \\
\text { tutional, personal, } \\
\text { collective) }\end{array}$ & $\begin{array}{l}\text { Remuneration, } \\
\text { training, commu- } \\
\text { nity development, } \\
\text { presenting results } \\
\text { in an easily } \\
\text { understandable } \\
\text { form, support, }\end{array}$ \\
\hline
\end{tabular}


Table 22.1 (continued)

\begin{tabular}{l|l|l|l|l}
\hline guideline & Consent & Participation & Data & Reciprocity \\
\hline $\begin{array}{l}\text { nature and extent } \\
\text { of participation } \\
\text { Draft is discussed } \\
\text { at a meeting with } \\
\text { the community }\end{array}$ & $\begin{array}{l}\text { research as well as } \\
\text { in the presentation } \\
\text { of the research }\end{array}$ & & $\begin{array}{l}\text { e.g. in the archiv- } \\
\text { ing of intangible } \\
\text { cultural heritage }\end{array}$ \\
\hline
\end{tabular}

RCAP Royal Commission on Aboriginal Peoples (Canada), DCI Dene Cultural Institute (Canada), ITC Inuit Tapirisat of Canada (Canada), SASI South African San Institute (South Africa), AIATSIS Australian Institute of Aboriginal and Torres Strait Islander Studies (Australia)

Participation is also understood as dialogue in the further course of the research process. A transparent, open exchange in clear, non-academic language should take place throughout the entire process from project planning to the presentation of the results. To ensure this, short interim reports are often recommended. The handling of data includes data of different kinds (e.g. raw data, interview data, media recordings). Access to research data and results should be provided for all stakeholders and interested parties through reports, databases, open access publications, etc. Type and extent of data use and data access should be discussed with all participants and implemented jointly.

As far as reciprocity is concerned, an appropriate remuneration for indigenous participants negotiated in advance and the calculation of travel costs, visa procurement and similar should be a matter of course. The sharing of research capacity, knowledge and skills and other intangible forms of reciprocity, for example, support for indigenous knowledge transfer and research beyond the scope of one's own project, are also frequently mentioned.

The evaluation of the research project should include an exchange on the continuing benefits and significance of the research results for the indigenous community. The following ethical recommendations for action can be applied to trace projects:

\section{Ethics Guide for Tracking Projects}

\section{Project Preparation}

\section{First Contacts and Contact Persons}

Ethical research "would be conducted in such a way that the organisations that are working at the grassroots level with the different San groups are given recognition, respect, and the opportunity to participate" (Ngakaeaja et al. 1998: 30).

- First of all, indigenous organizations, which may be able to refer to a specific community or experienced trackers, should be contacted.

- The organization concerned should have access to research proposals and drafts. 
- The research idea and the possible framework should be discussed and developed together with the community concerned and the proposed trackers.

- This exchange and relationship building is best done personally within the indigenous community.

- Researchers should familiarize themselves in advance with similar projects that have already taken place and the resulting experiences and expectations.

- Researchers should know and act on existing indigenous ethical guidelines such as the South African San Institute.

\section{Declaration of Consent}

"It was understood, upon analysis of past experiences, that in every single transaction involving traditional knowledge or practices, the need for full prior informed consent was perhaps the most important requirement." (Chennells 2009: 219)

The declaration of consent should not be designed in the form of a previously fully formulated information form, but should be seen as the result of an initial communicative negotiation process of the framework conditions in the sense of a "continual dialogue approach" (Kvale 1996: 114). Details of the following points, discussed in advance with indigenous project partners, are recorded in writing and signed:

- Contents and aims of the research

- Persons and institutions involved

- Possible advantages and disadvantages of participation

- Funding sources and sponsors

- Project scope and general conditions (location, time)

- Type of participation

- Type of expense allowance such as travelling expenses and remuneration for trackers, translators, etc.

\section{Research Design}

- Discussed with representatives/elders or other respected persons of a community.

- This can be used to initiate further discussions with members of the community and to find project partners.

- Sufficient time (several face-to-face meetings) should be allowed for establishing relationships and shaping the research framework.

- In addition to scientific methods, it makes sense to document methods of relationship building and indigenous participation from the outset (Tondu et al. 2014: 424). This can also be useful or necessary to apply for funding for longer projects. The duration of the project can be justified with the necessary time to establish relationships and the high importance of relationships in collaborative projects.

\section{Project Implementation}

\section{Training/Getting Familiar}


- Become familiar with the context of the tracks by means of test inspections and information on site.

- Contextual information:

- Room: e.g. light, climate and space conditions in caves

- Ecology: e.g. specific fauna

- Time/history: archaeological background

- The western researcher needs to become familiar with the indigenous tracking method in the field to be sensitized for interview and indigenous interpretation of the archaeological traces.

\section{Interpretation of the Footprints}

- Allow sufficient time for interpretation and communicative validation.

- As few interruptions and guiding questions as possible.

- Pauses and summarizing first insights offer possibilities for inquiries and concretization of individual points.

\section{Data Management}

- Photo, audio and video documentation of the interpretation process.

- Recordings can be used in many ways, e.g. for further analysis of traces and the trace-reading method in archaeological and indigenous contexts, but also for community reports, etc.

- Data storage accessible to all participants, if necessary a specially set up and indigenous group trained in dealing with databases, translation programs, etc.

\section{Reciprocity}

- Compensation of trackers and translators: wage agreed on in advance

- Structuring of the project into phases, interim reports, etc. for the indigenous community, continuous dialogue

- The usefulness of knowledge gained beyond the archaeological project, e.g. selfconfidence gained from results and teaching material for the dissemination of the tracking method in indigenous contexts

\section{Evaluation and Completion of the Project}

\section{Authorship}

- Identifying indigenous sources of knowledge

- Joint publication and naming of all authors

- Joint presentation of the results, depending on the target group (press, specialist audience, indigenous communities), e.g. through lectures, presentation of photos and films accompanying the project 


\section{Open Access}

- Open data access, sharing of results.

- For example, on suitable Internet platforms, as a blog, in freely accessible journals.

- An overview of journal databases, legal and financial aspects, etc. can be found, for example, on the website https://open-access.net.

\section{Further Use of the Research Results}

- Support of indigenous knowledge transfer, e.g. through summary results in local language (possibly in cooperation with the translation group).

- Final evaluation of the project, discuss the benefit/further use of the data and results.

\section{The Common Language}

Dialogic approaches are not only relevant from an ethical point of view but also necessary from a practical point of view in order for joint projects to succeed. Concrete communicative aspects include interview and interpretation, hypothesis formation and consensus, and communicative validation.

\section{Indigenous Interpretation and Interview}

A definition that also applies to trace projects describes the interview as a "contextually bound and mutually created story" (Fontana and Frey 2005: 696). The aim is to develop an informative story or hypothesis in dialogue with the interviewees, taking into account different contexts (technical, ecological, social). Thus the interpretation of the traces on site is to be understood in the broadest sense as an interview. An important question here is to what extent the interview is structured and in what form questions are asked. Since western categories and classifications are not exclusively used in a collaborative project, highly structured interview forms with questions formulated in advance are unsuitable. An inflexible concept would contradict many indigenous concepts of knowledge generation. The latter focus on learning through observation and stories (Lowe 2002; Bell 2009: 84) and are therefore more compatible with open forms of interviews. In semistructured interview forms, a rough structure (e.g. certain topic complexes) is given. At the same time, the course of the interview is flexible. This form of interview is particularly suitable for joint tracking projects.

Trace interpretation is a communicative process in which observations and experiences are discussed. Language reflects culture-specific experience, interpretation patterns and knowledge concepts. In the joint project, the indigenous language 
should therefore also be given a lot of space in the interview. Interim results can be summarized and discussed at regular intervals.

Communication is equally a means of data acquisition and validation. Validity in the sense of objectivity is often understood as the pole of a dichotomy, e.g.:

- Objective - subjective

- Quantitative - qualitative

- Fact - value/fiction

But objectivity unites many facets. It can arise both through impartiality or reflection on the nature of a research object and through intersubjective knowledge (Kvale 1996: 64). In the common process of interpreting the traces, dialogical intersubjectivity as rational discourse and reciprocal critique between the interpreters can lead to a consensus on a hypothesis.

In summary, the following points can serve as a guideline for the communicative interpretation of traces on site:

\section{Interview Guide for Joint Projects on Footprints}

\section{Preparation}

\section{Participants}

- Interview group consists of western researchers (one of whom ideally speaks the language of the indigenous trackers) and a group of two to three indigenous trace experts (one of whom may be able to provide a summary of observations in English).

- The focus should be on the dialogue between the indigenous trackers in order to interrupt the flow of interpretation as little as possible.

\section{Setting}

The interview should take place in places where the participant is most comfortable (DCI 1991). This requirement is not met for footprints in caves, so the following is important:

- Intensive preparation before the actual interview

- Getting to know the room (light, temperature, room conditions), e.g. through shorter test runs

- Background information on local environmental aspects (fauna, geological features, etc.)

- Planning of breaks.

Even in the case of open trace fields/track sites, comprehensive preparation and context information are important, on the one hand because of the above-mentioned aspect of familiarity and on the other hand because of the easier and more comprehensive possibilities of interpretation this makes possible. Therefore, a detailed preliminary discussion on the following points is also part of the preparation: 
- Background information (see above)

- Kind of the desired interpretations (e.g. number of individuals and action scenario in a defined range)

- Information on time, duration and location

- Required equipment

- Type of data recording/documentation and use of data

\section{Interview Conduct}

- Interim results of indigenous interpretations may occasionally be summarized.

- Summaries offer the opportunity to ask concrete questions on the spot, which can be incorporated into further interpretation.

- Semistructured interview form suitable: Certain topics are worked through; the type of information required is determined in advance. However, the order of the topics, pace, etc. is determined mainly by the indigenous way of working.

- Interview as a dynamic process: Possibilities for questions arise in the course of the conversation.

- In order to be able to recognize and use these possibilities, it is necessary to keep an eye on the type of interactions as well as the observed and communicated contents and previously formulated questions or main topics.

- Duration: The possibility of interruption should be given at all times.

\section{Media and Data Management}

- For further analyses, an audio recording of the interpretation or the summaries can be helpful in addition to archaeological and photographic methods of recording findings.

- In order to be able to understand the reference to individual imprints and features afterwards, video recordings are also suitable.

- Clear agreements on the evaluation, storage and use of this data should be made in advance.

- Images, audio and video recordings should be accessible to all research participants and (at least a few commonly selected files) should also be available to the indigenous communities concerned.

\section{Evaluation}

- Evaluation of the data: Individual sequences and summaries, e.g. on specific trace characteristics, can be evaluated by western researchers in consultation with indigenous experts.

- For a more in-depth analysis of interpretations and indigenous interpretation methods, evaluation and translation should be carried out by native speakers.

- Several people are needed for this complex and time-consuming work. A local translation group can take over this task. The remuneration of the translators can, for example, be based on the length of the media sequences processed.

The appropriate interview form and structure depends on the aim and content of the study, as well as on the time and cost factor: If the research framework is less 
extensive, e.g. indirect or only occasional direct contact or the interpretation of individual impressions or traces via photos and other media, more structured interview forms such as questionnaires with concretely formulated questions on individual characteristics are possible. However, this form leads to more clearly predefined and therefore limited statements, and even with such a form of cooperation, the above-mentioned points regarding a continuous open exchange and clear agreements on the use of data, etc. must be considered.

\section{Finding and Communicating Stories: Between Paper Talk and Fireside Talk}

So far, the importance of an open exchange between the project participants has been demonstrated. Finally, the question arises as to how the (hi)story of traces reads and the research process is communicated.

The research process was characterized by a variety of methods and relationships. Interest in the research and the results can be expressed by many groups, e.g. funders, academies, broader public, media and community of indigenous trackers. The narrative and media of the publication are correspondingly diverse. Not only the adaptation to recipients plays an important role but also traditional patterns of knowledge transfer. Which western and indigenous narrative forms do exist, and how can they be brought together? Traditional academic final reports that present facts are only one way of imparting knowledge.

\section{Research and Stories}

Knowledge and imagination, classification and narration are not contrary, but complementary. If research is not limited to the search for knowledge that can be expressed in quantifiable laws, but is understood as learning in a relational holistic understanding, then stories are comparable to research, because a story:

provides insight from observations, experience, interactions, and intuitions that assist in developing a theory about a phenomenon. (Kovach 2009: 102)

Narratives can offer orientation, and they establish connections between different generations and between man and the environment (Sommerville et al. 2010: 97). The strength of stories lies in:

structuring (...) beyond dichotomies between cultural/natural, human/inhuman, life/death and material/immaterial. (Porr and Matthews 2016: 261)

The dualism-dissolving property of stories can be useful in joint tracking projects, because: 
Fig. 22.2 George Aklah (Canada) giving his paper talk during the Prehistoric Human Tracks conference in Cologne/Mettmann 2017. (Photo H. Specht/J. Becker)

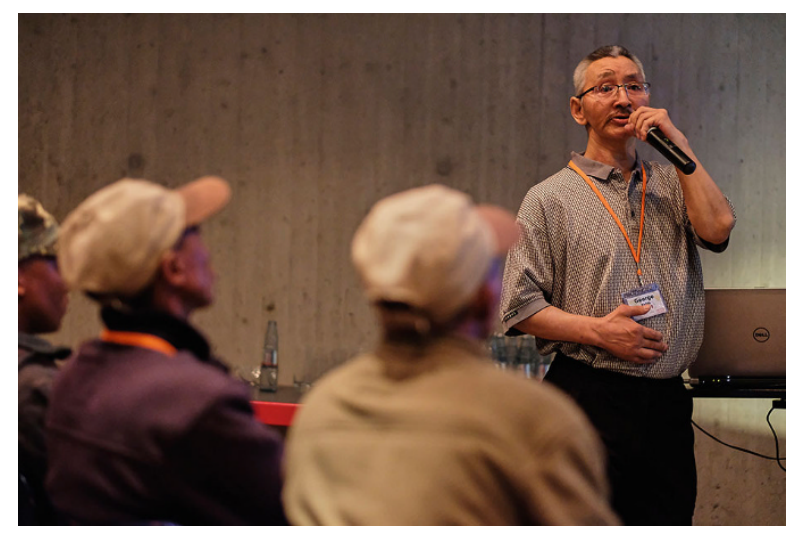

Fig. 22.3 Fireside talk during the Prehistoric Human Tracks conference in Cologne/Mettmann 2017. (Photo H. Specht/J. Becker)

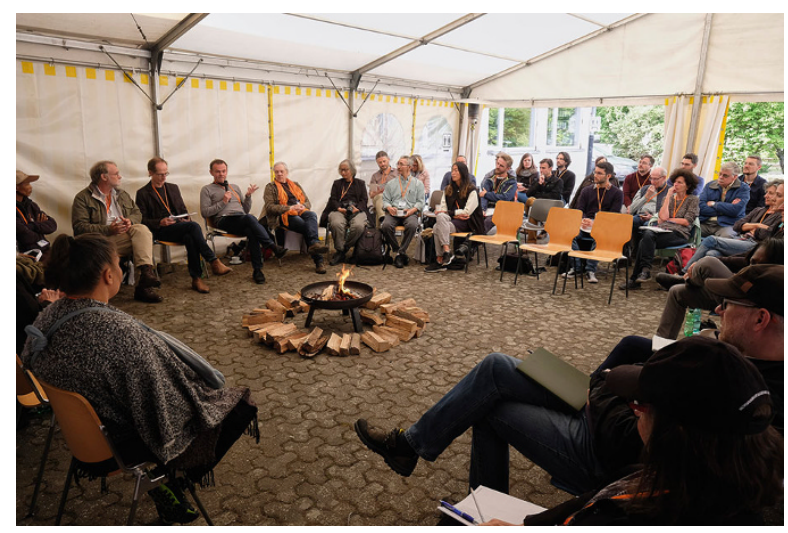

- The premise that every form of knowledge acquisition is narrative (Hendry 2010: 77) promotes dialogue between different epistemologies.

- The (hi)story of trace formation recorded in the soil directly connects man/individual and environment.

- It connects the past and the present.

In the trace project we have two stories: the research story and the researched story. Both are equally important and can be communicated both in written form as paper talk (Fig. 22.2) and in oral form as fireside talk (Fig. 22.3) or in a jointly conceived mixed form.

The paper talk focuses on the facts of the researched (hi)story. Paper talk means writing down a map of which steps we took and what we found along the way that we can pick up, analyse and present. The fireside talk offers more freedom of direct communication and exchange of experiences. It resembles a reflection on what steps we took, what we experienced and observed along the way, where we should go and what will guide us. 


\section{Oral Forms and Mixed Forms of Sharing Knowledge}

Smaller discussion groups, in which questions and knowledge on various aspects of a topic are discussed and in which each participant can contribute something, can orient themselves on indigenous methods such as the sharing circles (Lavallée 2009). As the conference on prehistoric human footprints has shown, such open forms of exchange can also be well integrated into western formats such as a conference programme.

A community report as the one which emerged from this conference (Ludwig et al. 2017) can be a mixture of oral and written forms of presentation. By conveying research as a living story, the report resembles oral narrative forms or can be easily combined with them. Design possibilities are manifold and project-specific. The report should in principle be based on the following points:

- Thematic key points of research and selection of relevant findings

- Interests of the target group

- Previous way of communication between research group and indigenous community

- Points mentioned in ethics guidelines such as transparency, nonacademic language, short summaries in indigenous language if necessary

- Joint reflection on the research process and design of the report

- Diversity of media, e.g. pictures, portraits, quotations, etc.

- Balance of professional and social/personal impressions

- Presentation of professional and social contexts and contexts

Similar to the community report, the relationship between the authors and the readers is also at the forefront in other forms of publication. Publications in an academic context raise the question of subjectivity: How can the acceptance of subjective experience and interpretation serve a research project? In what form are contents traditionally published, and what alternatives are conceivable?

\section{Alternative Forms of Writing}

Tilley describes interpretation as a process of contextualization. This refers to both the archaeological context and the context of the interpreter (Tilley 1993: 8). Often, however, the personal context of the interpreter is hidden, and the author appears as an omniscient, anonymous narrator. Narrative structures are linear sequences of problems, evidence discussion and a conclusion that reveals the "true meaning" of the evidence presented (Tilley 1993: 143).

A collaborative research project with indigenous trackers is in many ways an opportunity to use alternative forms of publication: Narrative relational approaches to knowledge and the acceptance of subjective knowledge are essential indigenous characteristics and thus also flow into the research process. Jointly formulated reports can be directed at different target groups, and different media can be used. Alternative forms of publication should not only be seen as adaptation to a diverse readership, but can also lead to new findings and questions on the research side (Van Dyke and Bernbeck 2015: 4). 
The way we write in the research process can already influence later forms of publication. Kovach uses a personal journal as a tool for meaning making:

This journal captured reflections on thoughts, relationships, dreams, anxieties, and aspirations in a holistic manner that related (if at times only tangentially) to my research. (Kovach 2009: 50)

A personal journal is particularly useful for the following reasons:

- Associative thinking and reflexivity are promoted, and the personal relationship to the topic is recorded.

- Some new correlations may not be revealed until a later look at the records.

- Excerpts from the journal (e.g. special situations/meetings) may be included in later publications.

- A personal journal can be an important source for the design of a community report as well as for the communicative reflection and presentation of the research process in general.

Many forms of design are conceivable, e.g. a collection of notes, sketches, descriptions of formative moments in the research process, associated keywords and many forms of design are conceivable. If we pursue a narrative approach to knowledge and assume that an object of research is not a dead object but speaks its own language that we want to understand, then it can make sense, similar to bilingual books, to juxtapose our own language (subjectivity) and the initially more or less foreign language (individual features/data and context of the object of research) on one page each. Thus, there is always enough space for reassignments. Connections between archaeological and subjective aspects can easily be established. The areas are not completely mixed, and yet both have their place.

How professional and subjective contents can be combined in the presentation of research results becomes clear in some publications of indigenous researchers. In Wilson's book Research is Ceremony, sections written in academic style alternate with sections written in letters to his children, relatives and friends. This makes content aspects in relational contexts visible to the reader and at the same time makes it easier for the author to freely write and clarify contexts by not seeing the reader as an anonymous counterpart (Wilson 2008). Kovach chooses descriptions of situations and landscapes to illustrate a context, and individual chapters are supplemented by thematically appropriate personal interviews (Kovach 2009).

Kovach's methods are particularly suitable for trace projects. For example, an atmospheric portrayal of the environmental context can provide the reader with a clearer, sensually perceptible picture of the contexts important for the interpretation of traces. Short interviews with indigenous trackers can illustrate interpretation methods and research contexts in a lively way.

Subjective elements in the text shift the balance of power between the omniscient anonymous narrator and the often equally anonymous reader. Alternative text forms can actively involve the reader in the process of knowledge production instead of exclusively presenting results. Such producer texts instead of consumer texts occur when an open text form is chosen: 
in which the author systematically attempts not to close the text down, to produce a spurious coherency but leaves gaps and fissures for the reader to fill in, threads and strands to follow up. (Tilley 1990: 146)

A possible alternative to closed, linear forms of text organization is the parallel texts already mentioned above in the personal journal. Here a phenomenon (e.g. a trace) can be viewed from different angles (e.g. objective description of the trace and its context, subjective sensory impressions, insights into research methods, possible reconstructed scenarios). Particularly in the case of traces that allow different interpretations, it would be possible to juxtapose the description of the traces and the interpretation context with fictitious action scenarios, or to combine these two aspects of the shared space with the aid of time leaps built into the text.

Even smaller thematic leaps within a text can contribute to an openly informative and multilayered text, without getting lost in individual fragments. In a "tangential text" (Tilley 1990: 144), a theme is followed, and at the same time branches of the main plot are used to trace different facets of the theme. Thus the text itself becomes a trace field, and the reader can actively participate in tracking down meaning.

A horizontal linking of diverse perspectives and contents in archaeological trace projects is important, but can also be a challenge if there is a danger of losing an overview of the structure. This can be avoided by a sketch or table of the connections. The Internet is a medium that makes it easier to horizontally network content in a variety of ways. Research can also be presented in the form of a home page (e.g. Tringham 2015) or a blog.

Different forms can be used in parallel or be combined in joint publications. From a practical point of view, it is useful to ensure easy accessibility as it is necessary from an ethical point of view. Which forms of publication are ultimately chosen is left to the creativity and resources of the researchers involved in a project.

\section{Conclusion}

From the first steps of approaching different epistemologies to the concrete implementation of joint interpretation of prehistoric human footprints up to the final presentation of the results, with this article, an attempt was made to look closer at the expert's steps and traces in collaborative research projects.

Not every aspect of this large thematic field could be investigated in detail. Accordingly, the aim of the article was to draw a rough sketch and to show various connecting approaches that could facilitate cooperation. The proposed recommendations are to be understood as drafts, which should be adapted to the requirements of concrete projects and to the work and cultural background of the respective experts involved.

In summary, the research process can be reflected as a joint journey. The topic of interpreting footprints is a point of common interest for western and indigenous trackers. So, the theme itself is the point in the meshwork where western and indigenous knowledge paths overlap - paths that come from different directions. 
Researchers who meet at this point bring with them their own stories, perspectives and methods. They become familiar with each other, and by entering into discourse, they create a communicative middle ground and decide together on the next steps.

Coming back to the question from which direction we begin our research, both answers are true: Our research starts with ourselves, and it starts with the common middle ground. Starting with ourselves means both self-reflection in the sense of "miskasowin - to go to the center of yourself and find your own belonging" (Kovach 2009: 49) - and our own scientific background. The first research idea usually emerges in the western archaeological context, and the research framework is to a large extent linked to western conditions (e.g. financial support, documentation, etc.). The way in which spaces of joint design can be opened up in the research process has become clear under ethical and communicative aspects and, in particular, in the diverse design possibilities of publications.

Framing and structuring research as well as being able to think outside the box and following trails in a meshwork are equally important. We come from different directions and bring with us different traditions, experiences and methods. Besides our differences, there are also points of convergence, and even differences do not have to stand in the way of a successful project.

A continual dialogue and participation in all stages of the process is both crucial and decisive. In order to initiate and maintain this dialogue, openness, respect and trust are necessary. The theoretical background of the joint research project should be based on a holistic paradigm and include various western approaches such as critical theories and qualitative methods as well as indigenous epistemologies. Accompanying quantitative scientific methods for documentation and further analysis of the footprints may be integrated in such a framework, but should not be the main focus of the research or used for the validation of indigenous knowledge.

How walking side by side can become walking together cannot be answered conclusively and will be tested in further projects. The research journey of the project not only leads to answers but also points out further nodes and paths. What influence joint projects have in indigenous communities and how long-term partnerships beyond one's own project can be established and shaped are just two examples of possible further questions.

However future collaborative projects may look like, we (especially as archaeologists) should never forget the ground under our feet while looking ahead for new points of data and argumentation. It bears the traces we explore as well as the traces our research leaves behind, and stories of interactions and connectedness are inscribed into it.

\section{References}

Agrawal, A. (1995). Dismantling the divide between indigenous and western knowledge. Development and Change, 26(3), 413-439.

Atalay, S. (2012). Community-based archaeology. In Research with, by, and for indigenous and local communities. Berkeley/Los Angeles/London: University of California Press. 
Bell, H. R. (2009). Storymen. Cambridge: Cambridge University Press.

Bennett, M. R., \& Morse, S. A. (2014). Human footprints: Fossilised locomotion? Cham: Springer.

Bishop, R. (1999). Kaupapa Maori research. An indigenous approach to creating knowledge. In N. Robertson (Ed.), Maori and psychology. Research and practice - The proceedings of a symposium sponsored by the Maori and psychology research unit (pp. 1-7). Hamilton: Maori and Psychology Research Unit.

Chennells, R. (2009). Putting intellectual property rights into practice: Experiences from the San. In R. Wynberg, D. Schroeder, \& R. Chennells (Eds.), Indigenous peoples, consent and benefit sharing. Lessons from the San-Hoodia case (pp. 211-228). Dordrecht: Springer.

Colwell-Chanthaphonh, C., \& Ferguson, T. J. (2008). Collaboration in archaeological practice: Engaging descendant communities. Walnut Creek: AltaMira Press.

Fontana, A., \& Frey, J. H. (2005). The interview. From neutral stance to political involvement. In N. K. Denzin \& Y. S. Lincoln (Eds.), The SAGE handbook of qualitative research (pp. 695-727). Los Angeles: SAGE Publications.

Grenier, L. (1998). Working with indigenous knowledge. A guide for researchers. Ottawa: International Development Research Centre. https://www.idrc.ca/en/book/working-indigenousknowledge-guide-researchers. Accessed 21 Jan 2020.

Hendry, P. M. (2010). Narrative as inquiry. The Journal of Educational Research, 103(2), 72-80.

Hollowell, J., \& Nicolas, G. (2009). Using ethnographic methods to articulate community-based conceptions of cultural heritage management. Public Archaeology, 8(2-3), 141-160.

Hountondji, P. J. (2002). Knowledge appropriation in a post-colonial context. In C. A. Odora Hoppers (Ed.), Indigenous knowledge and the integration of knowledge systems. Towards a philosophy of articulation (pp. 23-38). Cape Town: New Africa Books (Pty) Ltd.

Ingold, T. (2011). Part IV A storied world. In T. Ingold (Ed.), Being alive. Essays on movement, knowledge and description (pp. 141-165). Oxon/New York: Routledge.

Jones, A., \& Jenkins, K. (2008). Rethinking collaboration. Working the indigene-colonizer hyphen. In N. K. Denzin, Y. S. Lincoln, \& L. T. Smith (Eds.), Handbook of critical and indigenous methodologies (pp. 471-486). Los Angeles: SAGE Publications.

Kim, J. Y. (2008). Hominid ichnology: Tracking our own origins. Ichnos, 15, 103-105.

Kincheloe, J. L., \& Steinberg, S. R. (2006). Indigenous knowledges in education: Complexities, dangers, and profound benefits. In N. K. Denzin, Y. S. Lincoln, \& L. T. Smith (Eds.), Handbook of critical and indigenous methodologies (pp. 135-157). Los Angeles: SAGE Publications.

Kovach, M. (2006). Searching for arrowheads: An inquiry into approaches to indigenous research using a tribal methodology with a Nehiýaw Kiskeyihtamowin worldview. PhD thesis, University of Victoria, https://dspace.library.uvic.ca/handle/1828/2272

Kovach, M. (2009). Indigenous methodologies. Characteristics, conversations and contexts. Toronto/Buffalo/London: University of Toronto Press.

Kreiswirth, M. (1994). Tell me a story: The narrativist turn in the human sciences. In M. Kreiswirth \& T. Carmichael (Eds.), Constructive criticism: The human sciences in the age of theory (pp. 61-87). Toronto: University of Toronto Press.

Kvale, S. (1996). InterViews. An introduction to qualitative research interviewing. Thousand Oaks/London/New Delhi: SAGE Publications.

Lavallée, L. F. (2009). Practical application of an indigenous research framework and two qualitative indigenous research methods: Sharing circles and Anishnaabe symbol-based reflection. International Journal of Qualitative Methods, 8(1), 21-40.

Legat, A. (2008). Walking stories; leaving footprints. In T. Ingold \& J. L. Vergunst (Eds.), Ways of walking. Ethnography and practice on foot. Anthropological studies of creativity and perception (pp. 35-49). Hampshire-Burlington: Ashgate Publishing.

Liebenberg, L. (1990). The art of tracking. The origin of science. Claremont/Cape Town: David Philip Publishers.

Lockley, M., Roberts, G., \& Kim, J. Y. (2008). In the footprints of our ancestors: An overview of the hominid track record. Ichnos, 15, 106-125.

Lowe, P. (2002). Hunters and trackers of the Australian desert. Sydney: RHYW. 
Ludwig, B., Johannes, M., Lenssen-Erz, T., Pastoors, A. (2017). Prehistoric human tracks. International conference. Community report.http://www.tracking-in-caves-online.de/wp-con tent/uploads/sites/3/2017/12/Prehistoric_Human_Tracks_CR.pdf. Accessed 21 Jan 2020.

Lyons, N. (2011). Creating space for negotiating the nature and outcomes of collaborative research projects with aboriginal communities. Études/Inuit/Studies, 35(1/2), 83-105.

Ngakaeaja, M. et al. (1998). A San position: Research, the San and San organisations. In A. Bank (Ed.), Proceedings of the Khoisan identities and cultural heritage conference. Organised by the Institute for Historical Research, University of the Western Cape: Held at the South African Museum, Cape Town: 12-16 July 1997 (pp. 30-32). Cape Town: University of the Western Cape.

Porr, M., \& Matthews, J. (2016). Thinking through story. Archaeology and narratives. Hunter Gatherer Research, 2(3), 250-274.

Reyels, L., Ivanov, P., \& Weber-Sinn, K. (2018). Humboldt Lab Tanzania. Objects from the colonial wars in the Ethnologisches Museum, Berlin - A tanzanian-german dialogue. Berlin: Reimer.

Robinson, M. P. (1996). Shampoo archaeology: Towards a participatory action research approach in civil society. The Canadian Journal of Native Studies, XVI(I), 125-138.

Rouzaud, F., \& Jamet, H. (1993). Des "chasseurs de caribou" à la découverte des grottes ornées paléolithiques. Bulletin de la société préhistorique Ariège-Pyrénées, XLVIII, 23-30.

Smith, L. T. (1999). Decolonizing methodologies. London/New York: Zed Books; Dunedin: University of Otago Press.

Sommerville, C., Sommerville, K., \& Wyld, F. (2010). Martu storytellers: Aboriginal narratives within the academy. The Aboriginal Journal of Indigenous Education, 39, 96-101.

Studley, J. (1998). Dominant knowledge systems and local knowledge. In: Community-based mountain tourism: Practices for linking conservation with Enterprise. Synthesis of an electronic conference of the mountain forum April 13 - May 18. http://thunderbolt.me.uk/wordpress/wpcontent/uploads/Dominant+Knowledge+Systems+and+Local+Knowledge.pdf. Accessed 21 Jan 2020.

Tilley, C. (1990). On modernity and archaeological discourse. In I. Bapty \& T. Yates (Eds.), Archaeology after structuralism: Post-structuralism and the practice (pp. 127-152). London/New York: Routledge.

Tilley, C. (1993). Introduction: Interpretation and a poetics of the past. In C. Tilley (Ed.), Interpretative archaeology (pp. 1-27). Providence/Oxford: Berg Publishers.

Tondu, J. M. E., Balasubramaniam, A. M., Chavarie, L., Gantner, N., Knopp, J. A., Provencher, J. F., Wong, P. B. Y., \& Simmons, D. (2014). Working with northern communities to build collaborative research partnerships: Perspectives from early career researchers. Arctic, 67(3), 419-429.

Tringham, R. (2015). Creating narratives of the past as recombinant histories. In R. M. Van Dyke \& R. Bernbeck (Eds.), Subjects and narratives in archaeology (pp. 27-55). Boulder: University Press of Colorado.

Umbagai, L. (2017). Firesidetalk. Prehistoric human tracks international conference. Institute of Prehistoric Archaeology, Cologne, 11-13 May 2017.

Van Dyke, R. M., \& Bernbeck, R. (2015). Alternative narratives and the ethics of representation. An introduction. In R. M. Van Dyke \& R. Bernbeck (Eds.), Subjects and narratives in archaeology (pp. 1-26). Boulder: University Press of Colorado.

Wilson, S. (2008). Research is ceremony: Indigenous research methods. Black Point: Fernwood Publishing. 


\section{Guidelines}

Report of the Royal Commission on Aboriginal Peoples (RRCAP). (1996). Vol. 5. Renewal: A twenty-year commitment. Appendix E: Ethical Guidelines for Research, 294-297. https:// qspace.library.queensu.ca/bitstream/handle/1974/6874/RRCAP5_combined.pdf?sequence $=1$. Accessed 1 May 2019.

Guidelines for the conduct of participatory community research to document traditional ecological knowledge for the purpose of environmental assessment and environmental management, Dene Cultural Institute (DCI). (1991). http://www.wipo.int/export/sites/www/tk/en/databases/crea tive_heritage/docs/dci_guidelines.pdf. Accessed 1 May 2019.

Guidelines for Ethical Research in Australian Aboriginal Studies, Australian Institute of Aboriginal and Torres Islander Studies (AIATSIS). (2012). https://aiatsis.gov.au/sites/default/files/docs/ research-and-guides/ethics/gerais.pdf. Accessed 1 May 2019.

South African San Institute, South African San Institute (SASI). (2017). http://trust-project.eu/wpcontent/uploads/2017/03/San-Code-of-RESEARCH-Ethics-Booklet-final.pdf. Accessed 1 May 2019.

Tringham, R. Dead Women do tell Tales, http://ruthtringham.com/OLD/Ruth_Tringham/Dead Women_Do_Tell_Tales.html, https://webbrain.com/brainpage/brain/230E20DC-C9BC-74929B9C-297A384B4CCF. Accessed 6 May 2019.

Open Access This chapter is licensed under the terms of the Creative Commons Attribution 4.0 International License (http://creativecommons.org/licenses/by/4.0/), which permits use, sharing, adaptation, distribution and reproduction in any medium or format, as long as you give appropriate credit to the original author(s) and the source, provide a link to the Creative Commons license and indicate if changes were made.

The images or other third party material in this chapter are included in the chapter's Creative Commons license, unless indicated otherwise in a credit line to the material. If material is not included in the chapter's Creative Commons license and your intended use is not permitted by statutory regulation or exceeds the permitted use, you will need to obtain permission directly from the copyright holder. 